\title{
A Qualitative Investigation of the Effects of Mentoring: Teacher Narratives from Tianjin, China
}

\author{
Paul John Edrada Alegado (Corresponding Author) \\ Institute of International and Comparative Education, Beijing Normal University \\ 19 Xinjiekou Outer Street, Haidian District, Beijing, China
}

Tel: 010-58806183Ｅ-mail: pauljohnalegado24@yahoo.com

Received: June 29, 2018

doi:10.5296/jet.v5i2.13285
Accepted: July 16, 2018

Published: August 14, 2018

URL: http://dx.doi.org/10.5296/jet.v5i2.13285

\begin{abstract}
The uniqueness of this research captures the dynamics of mentoring relationship between mentors and mentees and to what extent they have an impact on each other. Based on the qualitative analysis from teacher interviews done in Tianjin, China, the mentees greatly benefit from this relationship evident on the pedagogical knowledge, classroom management skills and psycho-behavioral aspects that they perceived and reported. On the other hand, mentors highlighted the effect on their leadership capacity and the sense of validation they get from this relationship. This paper concluded that although the benefits may not be weighed exactly the same on both ends, the effects are fundamentally significant and still 'mutual'. The understanding of how teachers perceive and receive mentoring structures present in their school systems support and promote the literature on mentoring as professional development, induction, and an established practice that transcend vividly in a Chinese context.
\end{abstract}

Keywords: mentoring, mentor, mentee, mentoring relationship, Tianjin, Chinese context

\section{Introduction}

Teachers are crucial in every educational system and educational reform (Borg, 2003; European Commission, 2013; Henard, \& Leprince-Ringuet, 2008; OECD, 2009b). Thus, it is imperative to study the very basic elements that build and influence educators and teachers. In that sense, teachers' beliefs, practices and attitudes are equally important to understand and analyze in order to advance educational processes. They are intently connected with teachers' strategies for handling the daily challenges in their professional and personal lives while also molding students' learning atmosphere and impact student motivation and success. Moreover, it is through teachers that the outcomes of job-related policies can be achieved - like changes 
in curriculum for teachers' initial education or professional development.

Consequently, the very fundamental mission of education is high quality teaching that highly relies on teachers because it is through teaching that deliberately develops student learning outcomes (Hattie, 2009; Henard \& Leprince-Ringuet, 2008; Henard \& Rosevear, 2012; Seidel \& Shavelson, 2007; Singh \& Sarkar, 2015; Windschitl \& Sahl, 2002.). However, achieving this mission whilst cultivating teacher attitudes and teaching practices do not come naturally to teachers. Other factors contribute to this effect and there's a need to examine such. Specifically, this paper will focus on mentoring. It is normally used to portray or define a relationship between a less experienced individual, called a mentee or protégé, and a more experienced individual known as a mentor. Conventionally, mentoring is regarded as a dyadic, face-to-face, long-term relationship between a supervisory adult and a pupil that cultivates the mentee's professional, academic, or personal development (Donaldson, et al. 2000). Similarly, in teaching profession, such relationship is also replicated; typically between a senior teacher and a novice teacher. This type of mentoring relationship can be informal or formally appointed, which also varies in duration (long term or short) and the manner of which the relationship is convened either online or in person (Kasprisin et al. 2003; Packard, 2003b).

Thus, to help teachers, it is of great essence to provide their performance in the classroom with enormous support and aid from the very establishment of their careers as teachers or as they progress on their teaching careers. This kind of assistance can be in the shape of effective mentoring programs and such are proven as critical in inducting teachers into the profession and keeping them in the educational career. Also, mentorship can also play a key role in constantly nurturing the professional knowledge, skills and attitudes that the teaching force needs for them to educate and eloquently prepare students of the future. However, the literature on mentoring still lacks to characterize the dynamics of a mentoring relationship, and to what extent they help the mentors and mentees. These still remain as fundamental issues and questions for the field and for policymakers confronted with ambiguity about backing up such program.

\section{Literature Review}

The term 'mentor' was coined from the Greek mythology based on the name of an old man who Odysseus left responsible for his home and his son, Telemachus, while he departed for a long- year expedition. 'Mentor' helped the boy become a young man and on one occasion, saved his life (Wai-Packard, 2001). Thus, the normative definition of mentoring is based on emotional support and guidance, typically of a more mature person to a younger person. As briefly defined in the introductory part of this paper, mentoring can be simply described as the relationship of a mentor and a mentee or a protégé. Increasingly in the past literature, the definitions of mentoring have also been more distinctive and for the lack of a better word, becoming more "well-defined". For example, Zachary (2002) proposes that mentoring involves a passage of knowledge, enables personal development, encourages wiser choices, and eases the protégé during transitional periods. Similarly, Blandford (2000) defines mentoring also as a process through which knowledge and understanding, skills and abilities, may be passed on to less experienced practitioners. But further explains that mentoring is not in a way where mentors dominate the relationship. Rather it is built on negotiation and trust where constructive 
criticism, proper support and advice take place. Bell (2000) adds that a mentor is someone who helps a protégé to learn something he or she would have learned less, slow or left alone. On the other hand, Harnish \& Wild (1994) reflect that the nature of this relationship is mutual in the sense that both protégés and mentors can gain from each other. This factor specifically will also be attempted to be examined in the latter discussions on this paper; whether there is significant difference on teaching practices between mentees and mentors.

\subsection{Mentoring as Induction}

The model of ongoing support for a period after qualification through mentoring or other similar structures like coaching is well recognized and long been established in many professions, such as teaching and social work and is being more and more initiated by other organizations (McKimm, Jollie, \& Hatter, 2007b). Whether in teaching or not, entering practice in any profession in general poses a major challenge to newly or beginning qualified practitioners. It is a very critical and a foundational period that will shape the rest of one's future career. It is a period where an individual's knowledge, skills and attitudes he acquired during years of his formative education are finally applied into practice. It is also a transitional stage in which they normally experience stress and challenge because of the demands of the working environment and the expected skills and abilities one must possess. Thus, this stage is when a practitioner or a beginning teacher needs most guidance and support in order to acquire confidence and develop competence.

Mentoring and induction are two terms that are often interchangeably used. It is because researchers lack a clear definition of what induction is. But in some parts of research, induction can consist of as little as a one day orientation program where a senior teacher or officer acts as a mentor. This foundation has formed the concept of mentoring as induction (Strong, 2009; Fideler \& Haselkorn, 1999). Mentoring as induction is similarly a personal guidance provided by the school, usually by seasoned veterans, to beginning teachers in schools. The overall goal of induction is to give newcomers a local guide, but the content, quality and the duration of this program also fluctuate broadly. For example, duration and intensity, may be very different from program to program. They can be a single meeting between mentor and mentee at the beginning of a school year, to a highly-structured program involving frequent meetings, reduced number of course preparations, a seminar custom-made to the necessities of beginning teachers, great communication with the administrators and leaders, and collaboration with other teachers.

Entering teachers in the profession normally concentrate on the basics of what they are expected to teach. As they become more familiar with the many aspects and demands of teaching, they change their attention on how to teach most effectively and how the system functions. Therefore, with proper mentoring package, novice teachers can learn how to address both these aspects of "what" and the "how" through experts sharing their best teaching practices and institutional knowledge. Teacher's sense of efficacy and their professional growth actually improves and their relationship decreases the beginning teacher' feelings of isolation. Thus, helping them direct the complexities of the classroom and the system itself. Quality mentoring within induction can ultimately impact beginning teachers 
through various adjustments and phases of professional growth they experience early in their profession (Wechsler et.al, 2010). However, the role of the mentors is to guide novice teachers in a reflective manner and practice by providing classroom and teacher observation so they can better realize evidence-based instruction. The mentoring process used under formal induction programs produces a collaborative learning environment which fosters problem-solving between the mentor and the mentee. By such, mentors can help beginning teachers reach their full potential and thereby escalate the prospect of student success (Rivkin et. al, 2005; Rockoff, 2004).

\subsection{Mentoring as Professional Development}

Other sets of literatures support the central premise of mentoring as a form of professional learning. It is highly stemmed from the notion that most people may best ascertain learning process by watching, observing, doing, commenting and enquiring, rather than merely listening (Nicholls, 2012). In a dyad of relationship between a superior authority and a student, in most cases the intern, initial teacher trainee, or beginning teacher can be labelled as an individual who is 'initiated into the traditions, habits, rules, cultures, and practices of the community they are to join' (Merriam, 1982: p37). Understanding these habits, rules, and the likes require the learning of specific language, conventions, knowledge and patterns, the type of learning Schon (1983) calls 'knowing-in-action'. It is from this premise that mentoring of initial and post-service individuals is gaining ground as a significant method for professional learning.

A lot of research has pointed put the psychosocial ways, emotional and behavioral; in which mentees gain during a mentoring process. For example, McIntyre and Hagger (1996) exposed that mentees have significantly increased their confidence and self-esteem due to reduced feelings of isolation. It was also reported that their self-reflection and problem solving abilities have improved. Similarly, Bullough (2005) explicates that mentees gain confidence through mentorship and they eventually have increased morale and have more positive attitude towards teaching. On the other hand, Malderez, Hobson, Tracey \& Kerr (2007) pointed out that mentoring develops capabilities of beginning teachers on their behavior and classroom management skills and their ability to manage time and workloads. And lastly, mentees have become more adapt to the norms, standards and beliefs related to teaching and their organization (Edwards, 1998).

Other camps of literature provide support and characterize the effects of mentoring schemes in work-based learning programs. For example, Jones \& Jowett (1997) mention that facilitated mentoring schemes may be introduced to distinguish potential more efficiently, induct new staff more speedily, increase employee retention, help self-development and work-based learning programs such as continuous professional development or training programs, support organizational change, encourage personal development, to help individuals cope with transitions such as moving into a new job or role. Correspondingly, Williams (2000) identifies six things that are learned through mentoring. This includes politics of organization, norms, standards, the values system, ideologies and the history of organization. Knowing such can lead to increased job satisfaction. 


\subsection{Mentoring in the Chinese context}

In China, teacher mentoring practices have been becoming more prominent feature of professional development and teacher education (Wang \& Paine, 2001; Wang, 2001, 2002; Wu, Zhang \& Tian, 2009;). "Shituzhi or shitu daijiao" means mentoring in Chinese. In school organizations, it usually refers to mentoring novice or beginning teachers. This system of mentoring has been long part of Chinese tradition and most schools in the country have established formal mentoring programs. In fact, experienced teachers are required to help new teachers to prepare their lessons, observe their classes and evaluate their teaching impact (State Education Commission, 1994). Mentoring appears not only on a one-to-one basis but group mentoring as well, wherein new teachers learn from their more experienced colleagues through day-to-day collaboration and lesson observations, (Salleh \& Tan, 2013). For example, 'tuandui daijiao' known as group mentoring, 'jiaoyanzhu' which means teaching-research group or 'beikezhu' or lesson preparation group are equally designed for experienced teachers to teach novice teacher in groups where they meet and collaborate, usually with an assigned leader, in teaching-research activities, lesson planning, sharing of ideas and experiences with each other.

Because mentoring is highly based on teacher's education and experience, mentoring is also directly linked to the hierarchical structure of teachers in China. Tan (2013) names four classifications of teachers according to ranks: (1) third grade or new teachers; (2) second-grade or teachers with 3-5 years teaching service; (3) first-grade or advanced teachers with more than 5 years of teaching experience after school and district evaluation; and (4) senior-grade teachers with considerable lengthy service and excellence in the field. Subsequently, honorary titles are also bestowed to excellent teachers, separate from abovementioned official titles or ranks. The first one is called gugan which means 'backbone'. They are highly experienced with at least a second-grade title and usually experts from the teaching workforce. On the other hand, teji which means special-grade are teachers with exceptional service in teaching and leadership acknowledged by the school and their community. Typically, a novice teacher will be mentored by a gugan teacher (Salleh \& Tan, 2013). There is also a thing called 'gugan mentoring' wherein teachers with potential to become experts are mentored.

On the other hand, some researches in China have also used mentoring on its potential in foreign language teacher development or FLTD. Li (2006) has explicated on his empirical studies from ethnic colleges in China that mentoring has positive impact on the novice teachers' ability to teach efficiently, lessen the stress of work, develop a more positive belonging attitude towards the organization and facilitate their reflexive abilities about their work and personal lives.

Previous studies about mentoring do not address the dynamics between mentors and mentees, specifically what mentees actually learn and what mentors gain from such relationship. It is still an area of research that is suggestively weak and embryonic in the research on learning and teaching. 


\section{Theoretical Framework}

Mentoring relationships are complex and it is likely that such are influenced by multiple factors that need further investigation. Ragins and Kram (2007) define a mentoring relationship as an inherently dyadic and complex process, with the mentor and mentee each doing distinctive roles and duties in the relationship. However, the success of any mentoring relationship is also dependent on the behaviors of both the mentor and the mentee.

There are various theoretical models that reflect the mentor and mentee relationship and how mentoring benefits them mutually. First, Zey (1984) proposed a theoretical model called Mutual Benefits which was a variant of social exchange theory. The premise of this model is that individuals enter into and remain part of relationships to meet certain needs, for as long as they benefit from that very relationship. Such can be found typically from a mentor-mentee relationship. The mentee normally learns the job and its related political, organizational and cultural aspects of the school. The mentor becomes the source of organizational information; thus, the mentee's accomplishments can have a positive impact on the mentor's reputation so to speak. Through this symbiotic relationship, even the organization or the school can benefit to having an efficient functioning professional team, a fittingly socialized and amalgamated teachers, and, most significantly, a distinctive archetypal of professional or supervisory succession that promises the transfer of organizational values and culture to the next generation of employee. This theoretical framework is suitable to integrate the mentor and mentee which denotes the benefits exchanged between the two and can also include the organization.

Additionally, Kram (1983) conceptualized both career development and psychosocial aspects of mentoring. She defined career functions as "those aspects of the relationship that primarily enhance career advancement," such as sponsorship, exposure-and-visibility, coaching, protection, and challenging assignments (p. 614). Whereas, psychosocial functions are defined as "those aspects of the relationship that primarily enhance the sense of competence, clarity of identity, and effectiveness in the managerial role," such as role modeling, acceptance-and-confirmation, counseling, and friendship (p. 614). These aspects describe to which disposition the mentor and the mentee develop.

Other sets of literatures seem to have found the specificities of the exchange in knowledge, skills and attitude that come in a mentoring relationship. For example, Chao (1997) concludes that the mentor promotes the mentee through developing his performance, potential, and visibility within the organization. Levinson et al. (1978) highlight that the mentee can also gain knowledge while the mentor acquires loyalty and support from the mentees and more importantly, a sense of well-being from having passed on the knowledge to the next in line. On the other hand, Nemanick (2000) explicates that mentored individuals are more inclined to enjoy more advancement opportunities than their non-mentored counterparts. Overall, mentors and mentoring have a positive and prevailing impact on professional growth, career advancement, and career mobility for the protégé. Kwan and Lopez-Real (2005) reported based from their study of mentor's perceptions in Hong Kong that seventy percent have benefited professionally from mentoring. It showed that not only mentors benefitted but also 
mentees through self or serious reflection on their own professional practices. Similarly, researches based principally on mentors' experiences, proposes that mentoring beginning teachers may have a positive impact on the professional and personal development of mentors (Hagger \& McIntyre, 2006; Yeomans \& Sampson, 1994).

Through these previous frameworks on mentoring, distinguishing the existing process and reciprocal benefits to which mentoring can have an impact on becomes more concrete and sharper. Although the model is a wider scope and approach to the upshots of mentoring, it can provide a better perspective about mentoring practices or a development of mentoring systems in organizations.

\section{Research Questions}

The lack of literature on mentoring which discourses the complex dynamics between mentors and mentees, explicitly what mentees reciprocally learn and what mentors profit from such relationship prompt the author to initiate this research. These issues and gaps using the Chinese context is still an area of research that is suggestively neglected weak and emerging. Having contextualized mentoring above, this paper mainly investigates the following questions:

1) To what extent do mentees impact their mentors?

2) To what extent do mentors influence their mentee?

\section{Methodology}

This research utilized a qualitative analysis of semi-structured interviews to capture the impacts of mentoring to both mentors and mentees. A qualitative approach is deemed fit when the interest of in-depth understanding of human behaviors and beliefs within the contexts they transpire in are to be studied (Rubin \& Rubin, 2005). With this type of approach where non-numerical data are used, the research can focus on the 'quality' and the 'nature' of how people understand, behave, experience and feel about a construct or phenomenon.

\subsection{Sampling and the Participants}

The participants were from a summer program for teachers in Tianjin, China where I taught teaching methodologies to novice and experienced teachers. I employed a purposive sampling technique because not everyone participating the program are or have been mentors and mentees. Purposive sampling is a non-probability method of selection and its objective is to sample participants in a deliberately tactical way so those selected as samples are guaranteed to be relevant to the research topics and questions that will be formulated and investigated (Bryman, 2008). The program itself did not have any limitations in age and teaching experience because the goal of the program was mainly to improve their English language abilities and their teaching strategies. Thus, purposive sampling technique was employed to identify teachers who are currently mentoring a new teacher or had mentored a colleague in their faculty $(\mathrm{N}=7)$ and teachers who are currently mentees or had been mentored in their schools by an older colleague $(\mathrm{N}=7)$. 


\subsection{Ethics}

Because the program required participants to adhere to 'English Only Policy' all throughout the program where the research was conducted, the researcher was aware that some responses made were unclear or worded imperfectly. Thus, statements that were unclear were rephrased and were showed to the participants after the interview to ensure that their meanings stay the same and that such meanings are conveyed in the most effective way on this paper. Also, to protect the participants' confidentiality, this paper will use pseudonyms where 'MR' pertains as mentor and 'ME' refers to mentees. Each of the participant's pseudonyms are also assigned with a corresponding number. This manuscript was also sent back to the participants for review and permission.

\section{Findings and Discussion}

The findings of this research highlight the extent to which mentoring benefits both mentees and mentors. Mentees showed more competence and efficacy in their teaching practices which include classroom management, teaching pedagogy and more positive attitude towards teaching their students. Mentors on the other hand, although no effects on their teaching practices have been identified, they reported to have developed more confidence and practiced their leadership potential through such mentoring activities.

\subsection{Mentees}

Mentees reportedly gain so much from their mentoring systems at their respective schools. Mentors vary in their responsibilities based on the needs of the mentees and based on school norms or practice but typically, they check lesson plans by novice teachers and help them to develop it. ME7 noted "My mentor observes my class and gives me feedback. As a new teacher, I think it's important to know my weak points so I can improve it”. Similarly, ME1 said "My mentor taught me to improve my lesson plan. She taught me to provide more examples and more activities as much as possible. I think this is a really important aspect of lesson planning”.

The relationship can also include mutual observation. The mentees observe their mentor's class to learn how to effectively deliver a lesson plan, the difficulties in teaching a lesson or strategies in classroom management. On the other hand, the mentors also watch their mentees' classes and evaluate them with feedbacks and suggestions. Because of such dynamics that happen between the mentor and the mentee, this teaching model benefits the mentee through pedagogical aid and classroom management skills. ME2 stated:

My mentor exposed me to different ways of assessing whether my students really learn something or not. As Chinese, we only know of examinations. But my mentor is very creative. She asks students for group works, videos or art activities related to the topic. I think these are very innovative and interesting ways of evaluation.

Likewise, ME4 noted "When I observed her class, I was amazed how good she is with handling her class. She can easily calm down students who are naughty and noisy. She uses rewards and punishments to her students". ME6 also added "She challenges her students by asking many questions. Her lessons are not boring. She encourages them to really think. She 
gives them enough time”. ME3 stressed that:

I learn a lot from observing her class. Her teaching style is not based on the book or focused on the book. She is very creative and inventive. She lets the students learn by themselves, from peers, and from outside sources. But she is always there to help them when it gets hard or confusing.

Lester (2003) explicated that teachers' professional development is highly embedded on their actual day-to-day activities. Beginning teachers receive many prospects and opportunities to better themselves and their work through lesson observations and supervision from their mentors. It also gives them the chance to learn pedagogical ways and ideas from their mentors. The practice of peer lesson observations replicated through the dyadic mentoring relationships has shown to have a vital point on mentee's advancement professionally.

Other responses from mentees also include some behavioral and psychological aspects of mentoring. For example, ME5 stated:

My mentor told me that my role as a teacher is beyond the classroom. I remember she told me about gaokao period (national exam). The students and especially their parents are very worried and stressed, so she gives counseling and listen to them. Even when at home, she said that she receives phone calls and she thinks its normal. It became part of her life as teacher.

ME4 also added "My mentor cheers me up and motivates me whenever I feel down or stressed out about my work. She is like a sister to me".

\subsection{Mentors}

The responses that have been recorded from mentors reflect the effects on their leadership potential and the psychosocial impacts that come with it. Although leadership is widely used in different literatures, the definition is still ambiguous (Hallinger \& Heck, 1998; Riley \& Louis, 2000). Generally, teacher as leaders can be understood as influencing others by mobilizing and energizing (Danielson, 2006). Likewise, Bergeron (2006) defines a leader as a coach who trains others and assist them with their responsibilities and duties. This type of leadership was the general conception from the participants. Additionally, mentors believe mentoring can have a direct influence on their leadership potential. For example, MR3 evoked "Mentoring lets me exercise my role as a leader. They listen to what I have to say and practice them in their classrooms". Correspondingly, MR5 noted "Being a mentor is an honor and privilege. Not everyone is given the opportunity to lead or teach a colleague. It means the school believes in my skills and my professionalism. As a teacher, it makes me feel really accomplished".

Noe (1988) deemed that through mentoring, mentors can advance mentees' professional development by providing opportunities to exhibit competency and special skills and talents, and through assisting them in their daily tasks. For mentors, this translates to the lesson planning support, class observations, and feedback mechanisms. Psychosocially, mentors can 
develop novice teachers' competence by becoming a role model and encouraging them to adopt new behaviors or approaches. MR4 noted "I learned to become a role model because I want my mentee to learn based on what she sees, and not purely because I said so. I let my mentee watch and observe my class to show her how I manage my class".

Kram (1983) denoted that such psychosocial functions in a mentoring relationship involve the sense of competence, clarity of identity, and effectiveness in leadership roles. Mentoring relationships relate significantly and positively to how they perceive their jobs. This is evident from MR2 when he exclaimed that "In the teaching profession, there is no greater reward in knowing that you don't only teach students but you also teach the next generation of teachers". Comparably, MR1 said:

Because of the trust the school gave me, I feel really confident and a sense of validation on my work. I have been working as a teacher for 7 years now. I don't think of myself as an outstanding teacher, but when the school assigned me a mentor role, I feel like my work and teaching career have been finally recognized.

\section{Conclusion and Implications}

Koki (2000) regards teachers as valuable resources in education, for which high-quality implementation and performance in teaching and learning are very fundamental ingredients of educational advancement. The qualitative study of teachers from Tianjin suggests and supports the wealth of evidence about mentoring having impacts on both mentors and mentees. These dynamics of the mentoring relationship portrays how both ends or parties can enhance their potential and personal development as it unfolds. For mentees, this includes teaching practices teacher's attitudes, pedagogical improvement and psycho-behavioral benefits. On the other side of the spectrum is the mentors which reported to have tapped on their leadership potential and made more sense of their place in their organization. As one might argue, the effects when weighted are not technically of the same value, but they both mutually benefit from the relationship and that alone is fundamentally significant in the understanding and the promotion of mentoring frameworks. The results of this study suggest that if teachers are provided with effective mentoring training, they can implement their teaching learning process effectively and efficiently and have positive view on their teaching professions through the sense of validation and importance that it generates. Through gaining more perspective and understanding about mentoring, organizations and leaders can attach more value to mentoring programs whether in induction or as a form of professional development. Schools and leaders should support and provide guidance to make such programs more effectual and competent.

Mentoring is a way to pace the improvement of leadership, talent, skills, knowledge and attitudes. For example, professional development like mentoring that focuses on helping teachers can develop specific content knowledge (Desimone et al, 2002). Mentoring is one of the best ways to pass along the norms, values, knowledge that are central to the school's success. The entire organization benefits not only those mentors and mentees because its staff relationship and leadership methods are cautiously mentored. Thus, a strong mentoring culture can also be developed and transmitted. This strong culture ensures that past lessons 
and successful core values and practices will continue or even improve. Furthermore, the school system with an extensive formal or informal mentor-based information network can be more responsive to the growing challenges of the teaching profession and even provide more opportunities to grow and prosper.

\section{Acknowledgement}

I would like to acknowledge all the participants who took part on this research. Your contributions and insights made this paper possible. All research-related costs for this research was funded by Ming Yuan Education Research Grant Program. Lastly, I would also like to thank Valentina Parr for financing the publication costs of this project.

\section{References}

Bell, C. R. (2000). The mentor as partner. Training and Development, 54(2), 52.

Blandford, S. (2000). Managing Professional Development in Schools. Routledge, London.

Borg, S. (2003). Teacher cognition in language teaching: A review of research on what language teachers think, know, believe, and do. Language Teaching, 36(2), 81-109.

Bryman, A. (2008). Social Research Methods. (3rd ed.). Oxford University Press.

Bullough, R.V. (2005). Being and becoming a mentor: school-based teacher educators and teacher educator identity. Teaching and Teacher Education, 21(2), 143-155.

Chao, G. T. (1997). Mentoring phases and outcomes. Journal of Vocational Behavior, 51, $15-28$.

Clement, M., \& Vandenberghe, R. (2000) 'Teachers' professional development: a solitary or collegial (ad)venture?'. Teaching and Teacher Education, 16, 81-101.

Danielson, C. (2006). Teacher Leadership that Strengthens Professional Practice. Alexandria: ASCD.

Desimone, L. M., Porter, A. C., Garet, M. S., Yoon, K. S., \& Birman, B. F. (2002). Effects of professional development on teachers' instruction: Results from a three-year longitudinal study. Educational Evaluation and Policy Analysis, 24(2), 81-112.

Donaldson, S. I., Ensher, E. A., \& Grant-Vallone, E. J. (2000). Longitudinal examination of mentoring relationships on organizational commitment and citizenship behavior. Journal of Career Development, 26, 233-249.

Edwards, S. (1998). Openness, productivity and growth: what do we really know? Economic Journal, 108, 383-398.

European Commission (2013). The teaching and learning international survey (TALIS) 2013: Main findings from the survey and implication for education and training policies in Europe. Education and Training. Retrieved from:

http://ec.europa.eu/dgs/education_culture/repository/education/library/reports/2014/talis _en.pdf 
Fideler, E., \& Haselkorn, D. (1999). Learning the ropes: Urban teacher induction programs and practices in the United States. Belmont, MA: Recruiting New Teachers, Inc.

Freeman, C., O'Malley, K., \& Eveleigh, F. (2014). Australian teachers and the learning environment: An analysis of teacher response to TALIS 2013: Final Report. Melbourne: ACER

Hagger, H., \& McIntyre, D. (2006). Learning teaching from teachers: Realising the potential of school-based teacher education. Maidenhead: Open University Press.

Hallinger, P., \& Heck, R. H. (1998). Exploring the principal's contribution to school effectiveness: 1980-1995. School Effectiveness and School Improvement, 9(2), 157-191. https://doi.org/10.1080/0924345980090203

Harnish, D., \& Wild, J. A. (1994). Mentoring strategies for faculty development. Studies in Higher Education, 19(2).

Hattie, J. (2009), Visible learning: A synthesis of over 800 meta-analyses relating to achievement. New York: Routledge.

Henard, F., \& Leprince-Ringuet, S. (2008). The path to quality teaching in Higher Education. Programme Institutional Management for Higher Education, (October 2007), 1-50. Retrieved from http://www.oecd.org/dataoecd/10/60/41692318.pdf

Hénard, F., \& Roseveare, D. (2012). Fostering Quality Teaching in Higher Education: Policies and Practices. OECD, (September), 54.

Jones, C., \& Jowett, V. (1997). Managing Facilities. Butterworth Heinemann.

Kasprisin, C. A., Boyle-Single, P., Single, R. M., \& Muller, C. B. (2003). Building a better bridge: Testing e-training to improve e-mentoring programs for diversity in higher education. Mentoring \& Tutoring, 11(1), 67-78.

Koki, S. (2000). The role of teacher mentoring in educational reform. Pacific Resources for Education and Learning, (808), 1-6.

Kram, K. E. (1983). Phases of the mentor relationship. Academy of Management Journal, 26(4), 608-625.

Kwan, T., \& Lopez-Real, F. (2005). Mentors' perceptions of their roles in mentoring student teachers. Asia-Pacific Journal of Teacher Education, 33(3), 275-287.

Lester, J. H. (2003). Planning effective secondary professional development programmes. American Secondary Education, 32(1), 49-61.

Levinson, D. J., Darrow, C. N., Klein, E. B., Levinson, M. A., \& McKee, B. (1978). Seasons of a Man's Life. New York: Knopf.

Li, R. (2006). Mentoring as a supportive way for novice teachers in foreign language Teacher development: a case study in an ethnic college in China. Journal of Language Teaching and Research, 7(2), 318-327. 
Malderez, A., Hobson, A. J., Tracey, L., \& Kerr, K. (2007). 'Becoming a student teacher: core features of the experience'. European Journal of Teacher Education, 30(3), 225-248.

McIntyre, D., \& Hagger, H. (1992). Professional development through the Oxford Internship Model. British Journal of Educational Studies, 40, 264-283.

McKimm J., Jollie, C., \& Hatter, M., (2007b). Mentoring: theory and practice. NHSE: Imperial College School of Medicine.

Merriam, S. (1983). Mentors and protégés: a critical review of the literature, Adult Education Quarterly, 33, 161-73.

Nemanick, R. C., Jr. (2000). Comparing formal and informal mentors: does type make a difference? Academy of Management Executive, 14(3), 136-138.

Nicholls, G. (2012). Mentoring: the art of teaching and learning. Kogan Page Limited.

Noe, R. A. (1988). Women and mentoring: a review and research agenda. Academy of Management Review, 13, 65-78.

OECD (2009b). Creating effective teaching and learning environments: first results from TALIS. OECD: Paris.

Packard, B. W. (2003b). Web-based mentoring: challenging traditional models to increase women's access. Mentoring \& Tutoring, 11(1), 53-65.

Ragins, B. R., Kram, K. E. (Eds.). (2007). The handbook of mentoring at work: theory, research, and practice. Thousand Oaks, CA: Sage.

Riley, K. A., \& Louis, K. S. (Eds.). (2000). Leadership for change and school reform. Routledge, London. https://doi.org/10.4324/9780203465882

Rivkin, S. G., Hanushek, E. A., \& Kain, J. F. (2005). Teachers, schools and academic achievement. Econometrica, 73(2) 417-458.

Rockoff, J. E. (2004). The impact of individual teachers on student achievement: Evidence from panel data. The American Economic Review, 94(2), 247-252.

Rosenholtz, S. (1989) Teachers' Workplace: The Social Organization of Schools. New York: Longman.

Rubin, H. J., \& Rubin, I. (2005). Qualitative interviewing: the art of hearing data. Thousand Oaks, CA: Sage Publications.

Salleh, H., \& Tan, C. (2013). Novice Teachers Learning from Others: Mentoring in Shanghai Schools. Australian Journal of Teacher Education, 38(3).

Schon, D. (1983). The Reflective Practice. Basic Books, New York.

Seidel, T., \& Shavelson, R. J. (2007). Teaching effectiveness research in the past decade: the role of theory and research design in disentangling meta-analysis results. Review of Educational Research, 77(4), 454-499. 
Singh, R., \& Sarkar, S. (2015). Does teaching quality matter? Student learning outcome related to teaching quality in public and private primary schools in India. International Journal of Educational Development, 153-163.

State Education Commission. (1994). Opinions on developing primary school new teacher training during probation, in: Encyclopedia on education law and regulations in the People's Republic of China (pp. 1773-1774). Beijing, Chinese Law Encyclopedia Press, 1998, in Chinese.

Strong, M. (2009). Effective teacher induction and mentoring: assessing the evidence. New York, NY: Teachers College Press.

Tan, C. (2013). Learning from Shanghai: lessons on achieving educational success. Dordrecht: Springer.

Wai-Packard, B. (2001). Definition of mentoring. Management, 2000-2002.

Wang, J. (2001). Contexts of mentoring and opportunities for learning to teach in a comparative study of mentoring practice. Teaching and Teacher Education, 17, 51-73.

Wang, J. (2002). Learning to teach with mentors in contrived contexts of curriculum and teaching organisation: experiences of two Chinese novice teachers and their mentors. Journal of In-Service Education, 28(2), 339-374.

Wang, J., \& Paine, L. W. (2001). Mentoring as assisted performance: a pair of Chinese teachers working together. The Elementary School Journal, 2(102), 157-181.

Wechsler, M. E., Caspary, K., Humphrey, D. C., \& Matsko, K. K. (2010). Examining the effects of new teacher induction. Menlo Park, CA: SRI International.

Williams, J. (2000). Mentoring for law enforcement. FBI Law Enforcement Bulletin, 69(3), 19-25.

Windschitl, M., \& Sahl, K. (2002). Tracing teachers' use of technology in a laptop computer school: the interplay of teacher beliefs, social dynamics, and institutional culture. American Educational Research Journal, 39(1), 165-205.

Wu, G., Zhang, C., \& Tian, L. (eds.) (2009). Curriculum leadership and school-based innovation: interpreting Shanghai Jingan Education College Affiliated School. Shanghai: East China Normal University Press.

Yeomans, R., \& Sampson, J. (Eds.). (1994). Mentorship in the primary school. London: Falmer Press.

Zachary, L. J. (2002). The role of teacher as mentor. New Directions for Adult and Continuing Education, 93.

Zey, M. G. (1984). The mentor connection. Homewood, IL: Dow-Jones-Irwin. 


\section{Copyright Disclaimer}

Copyright reserved by the author(s).

This article is an open-access article distributed under the terms and conditions of the Creative Commons Attribution license (http://creativecommons.org/licenses/by/3.0/). 